\title{
Frequency Measurement of the Prototype \\ Storage Ring Stainless Steel Single Cell Cavity
}

July 29, 1992

Elizabeth A. Reisinger

RF Group

Advanced Photon Source

Frequency measurements were made on the stainless steel single cell cavity with various port terminations, using two small loops. The cavity contains six larger ports. The top and bottom ports have a diameter of $144 \mathrm{~mm}$, the front and back ports (beam ports) have a diameter of $140 \mathrm{~mm}$, and the two side ports have a diameter of $120 \mathrm{~mm}$. The cavity also has four smaller ports of diameter $34.8 \mathrm{~mm}$, which contain an E-probe, a H-loop, and two field probes.

The frequency measurements for the fundamental mode are as follows:

1. All large ports covered with blank flanges. Frequency is $352.28 \mathrm{MHz}$.

2. Input coupler in side port and all other large ports covered with blank flanges. Frequency is $352.30 \mathrm{MHz}$.

3. Tuner (with plunger in the minimum position) in top port and all other large ports covered with blank flanges. Frequency is $352.39 \mathrm{MHz}$.

4. Tuner (with plunger in the minimum position) in top port, input coupler in side port, and all other large ports covered with blank flanges. Frequency is $352.42 \mathrm{MHz}$.

5. Tuner (with plunger in the maximum position) in top port, input coupler in side port, and all other large ports covered with blank flanges. Frequency is $353.26 \mathrm{MHz}$. 


\section{DISCLAIMER}

This report was prepared as an account of work sponsored by an agency of the United States Government. Neither the United States Government nor any agency thereof, nor any of their employees, make any warranty, express or implied, or assumes any legal liability or responsibility for the accuracy, completeness, or usefulness of any information, apparatus, product, or process disclosed, or represents that its use would not infringe privately owned rights. Reference herein to any specific commercial product, process, or service by trade name, trademark, manufacturer, or otherwise does not necessarily constitute or imply its endorsement, recommendation, or favoring by the United States Government or any agency thereof. The views and opinions of authors expressed herein do not necessarily state or reflect those of the United States Government or any agency thereof. 


\section{DISCLAIMER}

Portions of this document may be illegible in electronic image products. Images are produced from the best available original document. 
When the plunger is in the minimum position, it rests $28 \mathrm{~mm}$ above the inside wall of the cavity. In the maximum position, it rests $33.5 \mathrm{~mm}$ below the inside wall of the cavity.

As more components are installed in the cavity, the volume of the cavity is reduced, and thus, a slight increase in frequency is observed. These frequency shifts are shown in Table 1, and the frequency plots for the above five cases are shown in Figures 1-5. A decrease in the unloaded $\mathrm{Q}$ value for the cavity is also seen as more elements are present in the cavity. The $\mathrm{Q}$ values for the different cases described above are shown in Table 1. Furthermore, the unloaded $Q$ value for the stainless steel cavity with all large ports covered with flanges is approximately two and one half times smaller than that previously measured for the copper prototype cavity with a similar setup.

Movement of the tuner plunger into and out of the cavity alters the resonating frequency. Frequency measurements were made with the stainless steel cavity and a $115 \mathrm{~mm}$ diameter tuner at various plunger depths. The frequency effect due to the movement of the tuner is shown in Figure 6.

A perturbation coefficient, $C$, relating the frequency and volume change can be calculated where

$$
\frac{\Delta \omega}{\omega}=C \frac{\Delta V}{V}
$$

The dimensions of the $352 \mathrm{MHz}$ stainless steel cavity are identical to the dimensions of the copper prototype cavity. Thus, the volume $(V)$ of the cavity used in the calculations is $0.116 \mathrm{~m}^{3}$ and the volume perturbation $\left(\frac{\Delta V}{V}\right)$ is $8.95 \times 10^{-5}$ per $\mathrm{mm}$ of plunger inserted into the cavity. 
The perturbation coefficients are as follows:

1. Movement of the plunger from the minimum position at $-28 \mathrm{~mm}$ (the inside wall of the cavity is used as the reference point of $0 \mathrm{~mm}$ ) to $-24 \mathrm{~mm}$ results in a frequency change of $0.019 \mathrm{MHz}$. The perturbation coefficient, $C_{1}$, is -0.15 .

2. Movement of the plunger from $-24 \mathrm{~mm}$ to $-20 \mathrm{~mm}$ results in a frequency change of $0.025 \mathrm{MHz}$. The perturbation coefficient, $C_{2}$, is -0.20 .

3. Movement of the plunger from $-20 \mathrm{~mm}$ to $0.5 \mathrm{~mm}$ results in a frequency change of $0.199 \mathrm{MHz}$. The perturbation coefficient, $C_{3}$; is -0.31 .

4. Movement of the plunger from $0.5 \mathrm{~mm}$ to $11 \mathrm{~mm}$ results in a frequency change of $0.159 \mathrm{MHz}$. The perturbation coefficient, $C_{4}$, is 0.48 .

5. Movement of the plunger from $11 \mathrm{~mm}$ to $18.5 \mathrm{~mm}$ results in a frequency change of $0.136 \mathrm{MHz}$. The perturbation coefficient, $C_{5}$, is 0.58 .

6. Movement of the plunger from $18.5 \mathrm{~mm}$ to $27.5 \mathrm{~mm}$ results in a frequency change of $0.179 \mathrm{MHz}$. The perturbation coefficient, $C_{6}$, is 0.63 .

7. Movement of the plunger from $27.5 \mathrm{~mm}$ to the maximum position of $33.5 \mathrm{~mm}$ results in a frequency change of $0.122 \mathrm{MHz}$. The perturbation coefficient, $C_{7}$, is 0.64 .

These perturbation coefficients can be averaged to obtain an average inward perturbation coefficient $C^{i n}=0.57$ and an average outward perturbation coefficient $C^{\text {out }}=-0.27$.

The average outward perturbation coefficient for the plunger positions above the inside wall is similar to that previously estimated. The average inward perturbation coefficient, however, is $40 \%$ lower than that previously estimated. Likewise, the maximum tuning range of the stainless steel cavity and $115 \mathrm{~mm}$ diameter tuner combination is $0.84 \mathrm{MHz}, 0.60 \mathrm{MHz}$ for $33.5 \mathrm{~mm}$ of inward travel and $0.24 \mathrm{MHz}$ 
for $28 \mathrm{~mm}$ of outward travel. This tuning range is half of the previously estimated range. Thus, as evidenced in the lower inward perturbation coefficients and decreased tuning range, the change in frequency per $m m$ of plunger inserted into the cavity is not as great as previously expected. 


\section{Table 1}

All ports flanged

Input coupler only

Tuner only $(-28 \mathrm{~mm})$

Input coupler and tuner $(-28 \mathrm{~mm})$

Input coupler and tuner $(33.5 \mathrm{~mm})$
$f(M H z) \quad \Delta f(M H z) \quad \mathrm{Q}$

352.28

17467

352.30

0.02

16941

352.39

0.11

17473

352.42

0.14

16777

353.26

0.98

11535 


\section{I วxn8ิก}

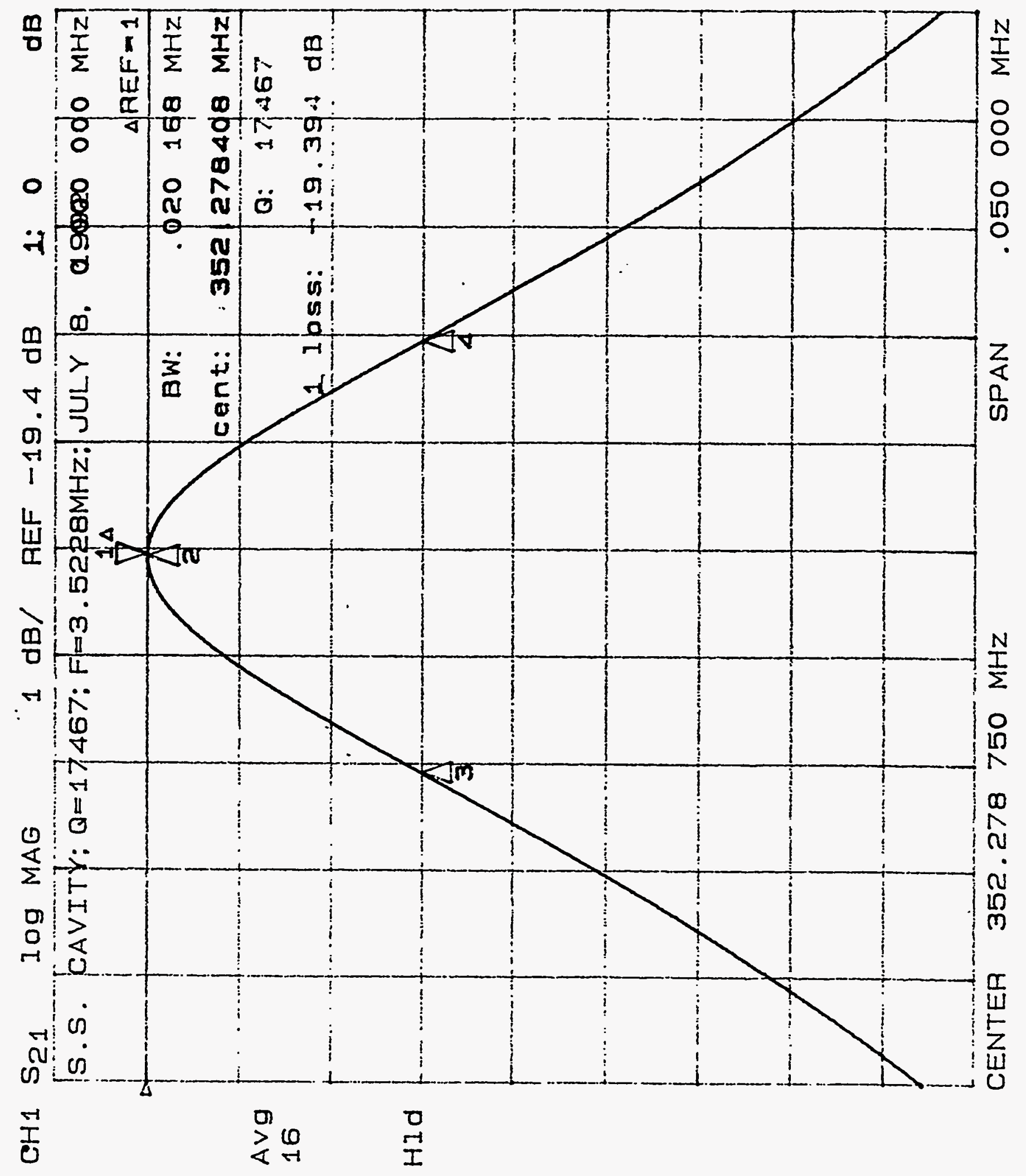




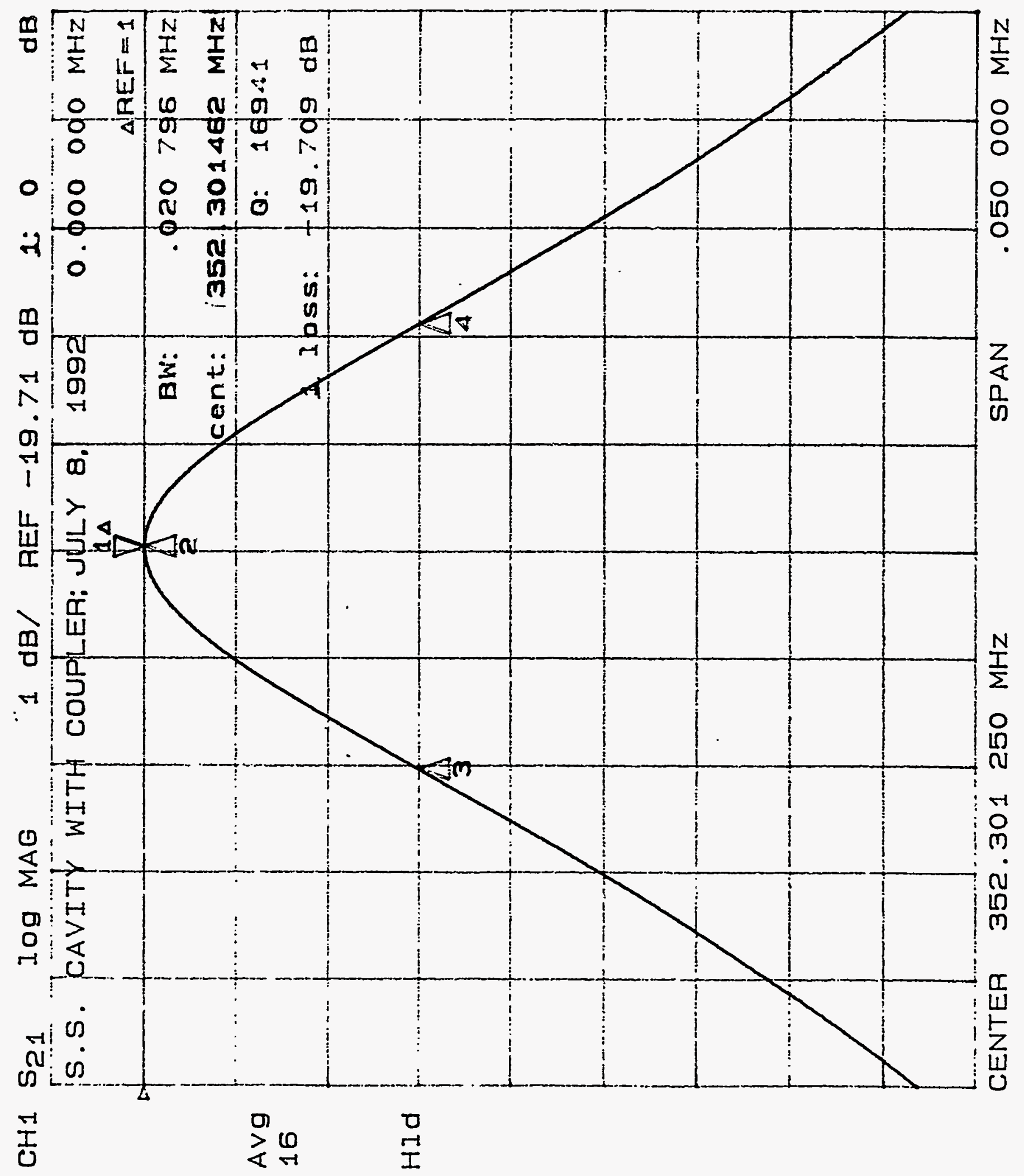




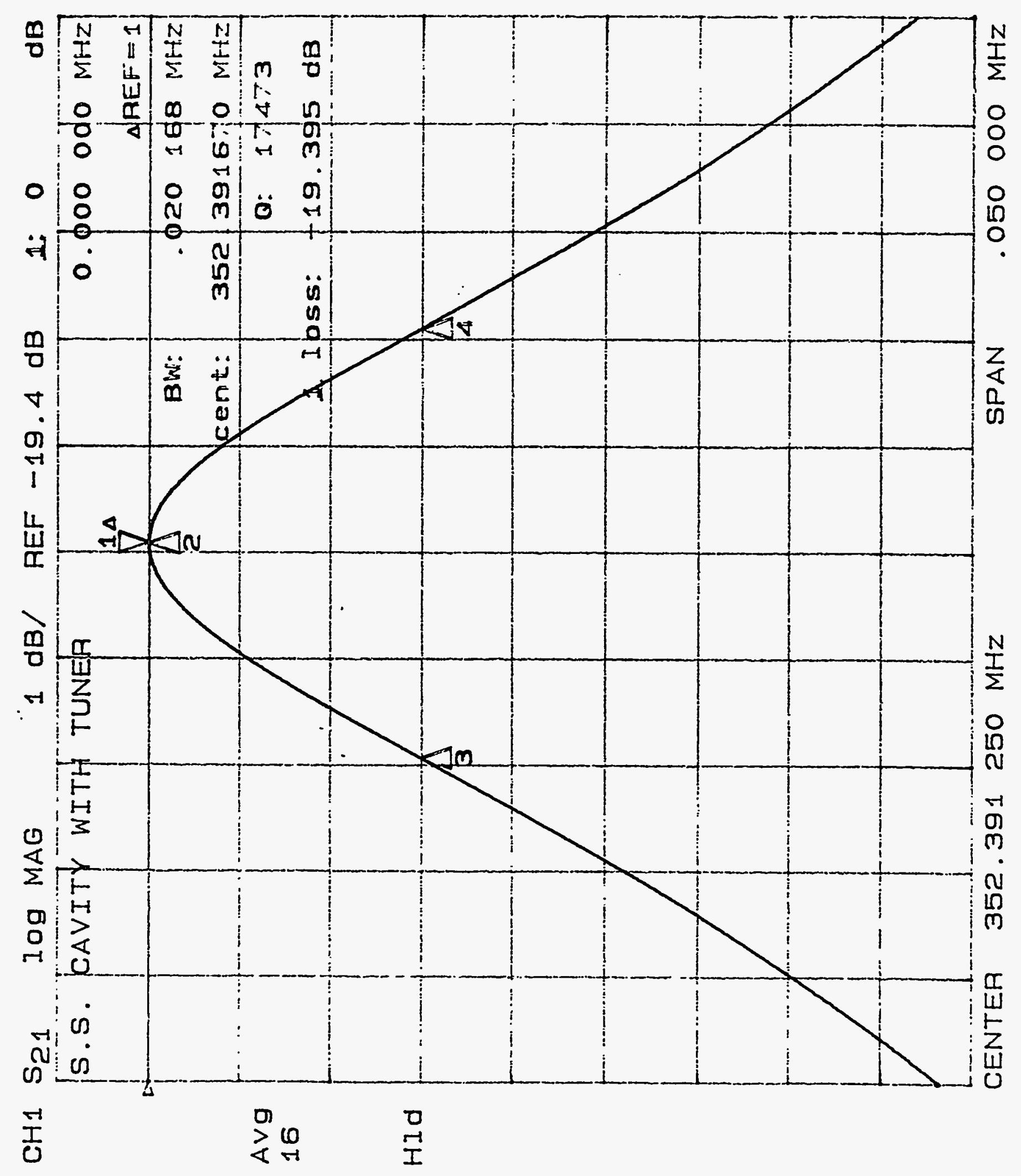




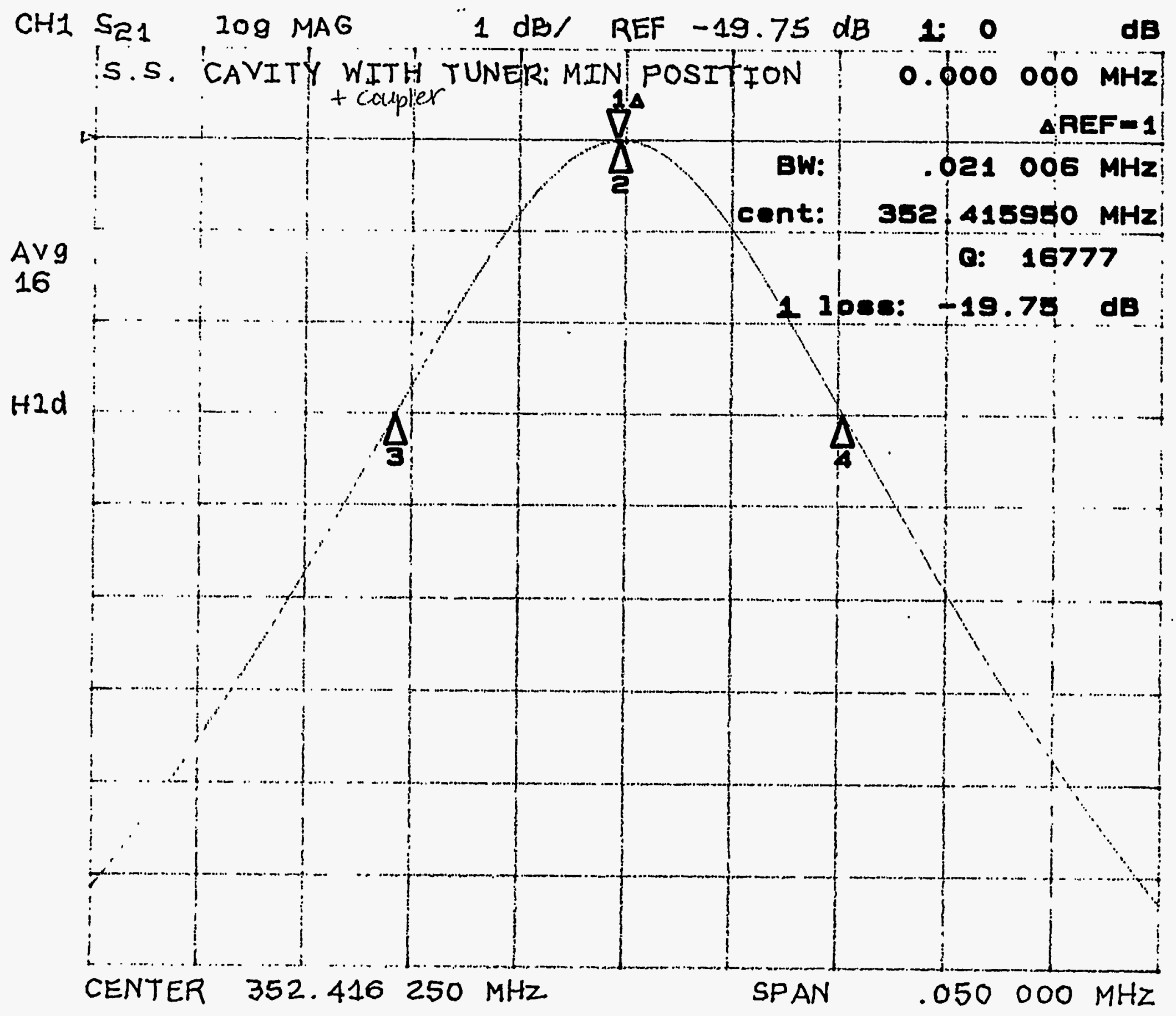




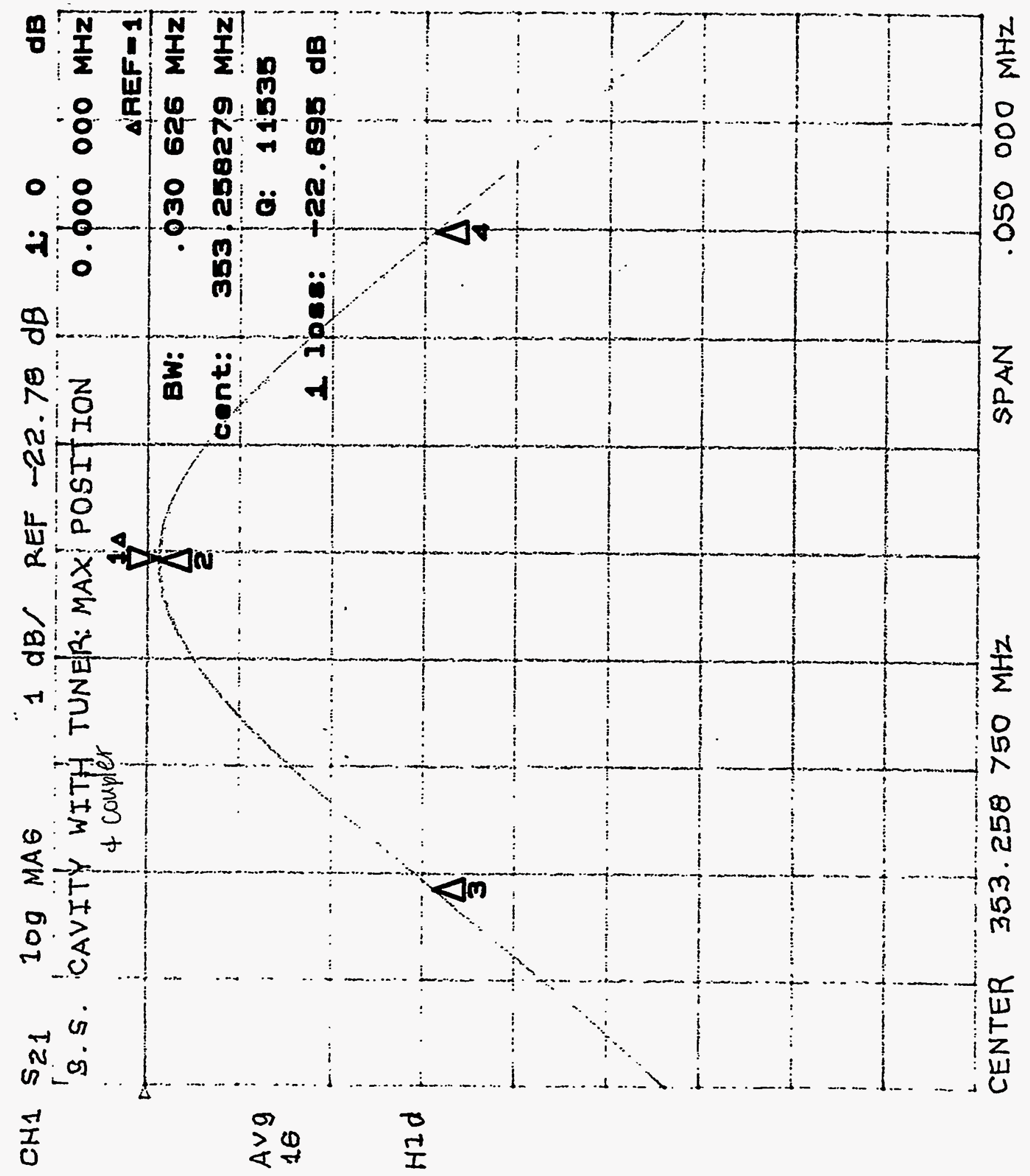


Frequency Effect Due to Tuner Position

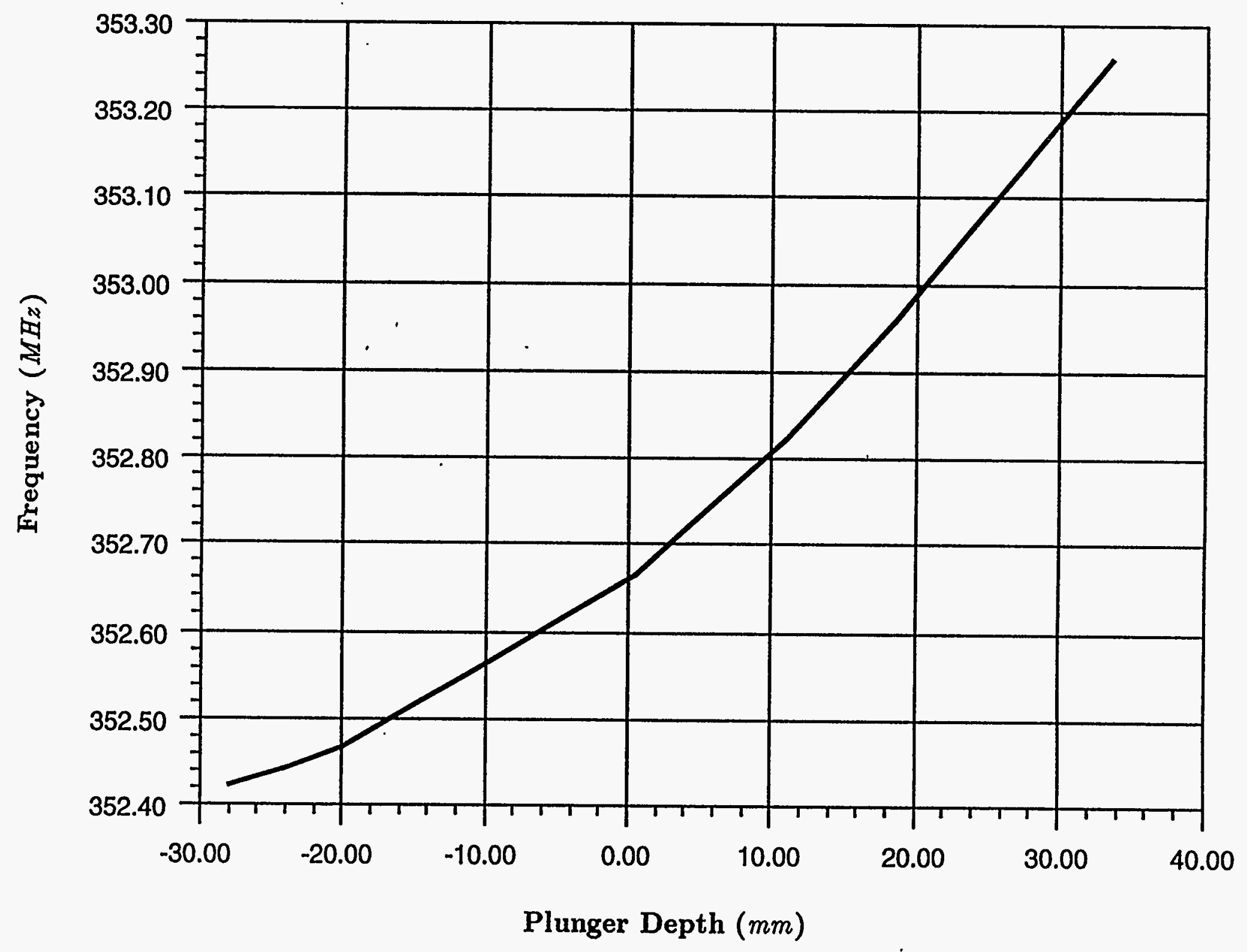

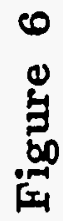

